\title{
COMMENT
}

MILITARY Two views of the changing impact of science on warfare $\mathbf{p . 1 5 6}$
BRAIN A compelling personal take on the science of anxiety $\mathbf{p} .157$
Music In conversation with an artist inspired by his own tinnitus p.159
BIAS Studies of gender and research impact should exclude self-citations $\mathbf{p} \mathbf{. 1 6 0}$

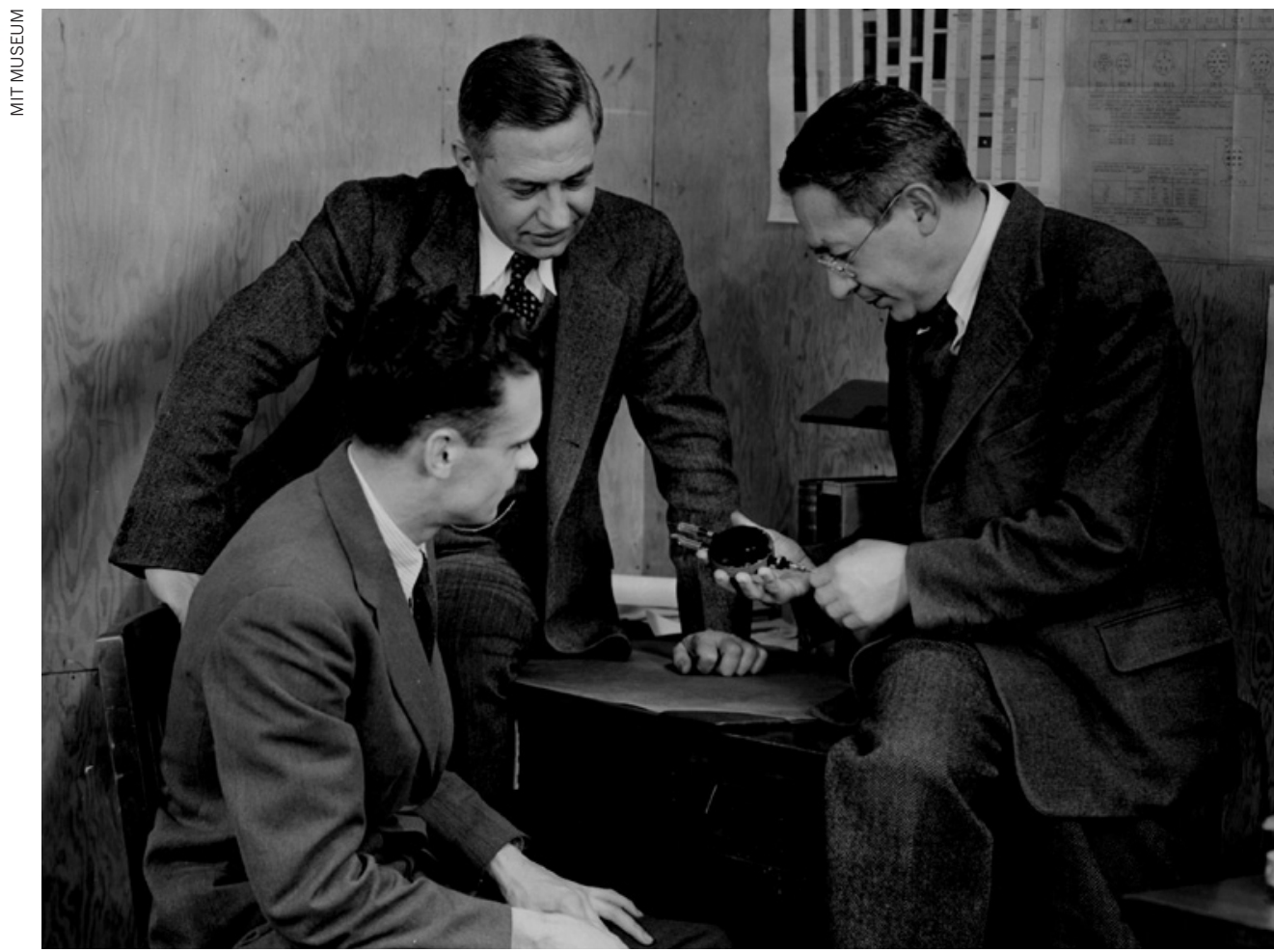

Physicists Edward Bowen (left), Lee DuBridge (centre) and I. I. Rabi work on a cavity magnetron in the 1940s.

\section{Shut up and calculate!}

\section{Practical, interdisciplinary ways of working forged during the Second World War had a lasting impact on a generation of physicists and their findings, says David Kaiser.}

$\mathrm{O}$ 17 October 1940, Karl Compton, president of the Massachusetts Institute of Technology (MIT) in Cambridge, made a hasty telephone call from Washington DC to a colleague back on campus. Could MIT spare some modest space to host an urgent, top-secret defence project? After making some quick assessments, Compton's assistant reported that MIT could shuffle some other laboratories to accommodate the facility. With that phone call, the Radiation Laboratory, or 'Rad Lab', was born. The laboratory had an enormous impact on the course of the Second World War. Arguably, its impact on science was even greater.
Within weeks of Compton's call, a skeleton staff at the Rad Lab was hard at work trying to improve on a British-designed cavity magnetron, which they hoped could become the centrepiece of a type of short-wavelength radar. When the laboratory began operation - more than a year before the United States entered the Second World War - the staff consisted of 20 physicists, three security guards, two stockroom clerks and a secretary. By the war's end, the lab had swollen to 4,000 people and was managing development contracts worth US $\$ 1.5$ billion (nearly $\$ 20$ billion in 2013 dollars) ${ }^{1}$.

The Allied nuclear-weapons project, code-named the Manhattan Project, grew even faster. Again building on early insights from a British team, the Manhattan Project, coordinated from the Los Alamos laboratory in New Mexico, ballooned to encompass 125,000 people working at 31 facilities across North America. By the time the atomic bombs were dropped on Hiroshima and Nagasaki in August 1945, the project had cost $\$ 1.9$ billion (about $\$ 25$ billion today) ${ }^{2}$. Together, the radar and atomic-bomb projects amounted to about $1 \%$ of US military expenditure during the war: modest on the scale of defence appropriations, but utterly unprecedented for the academic scientists and engineers caught up in the war projects.

And it was more than just the 
budgets that grew. In both projects, physicists, chemists, metallurgists and their colleagues found themselves working in huge groups with larger-than-life equipment. Isotope-separation plants in Oak Ridge, Tennessee, stretched the length of a city block; the nuclear-reactor facilities in Hanford, Washington, required more than half a billion cubic metres of concrete.

After the war, many physicists dismissed their work on such sprawling wartime projects as temporary distractions: an important but limited hiatus from their 'real' scientific research. One Rad Lab veteran even composed a song soon after the war closing with the memorable line, "Oh, dammit! Engineering isn't physics, is that plain? Take, oh take, your billion dollars, let's be physicists again".

Despite the songwriter's plea, scientists did not return to the antebellum status quo. Instead, many characteristics of the wartime projects became the new normal, even in peacetime. The war cast a long shadow on how science is organized and funded, and even on the methods and questions that many scientists pursued throughout their careers.

\section{COMMON PURPOSE}

Until the war, most scientific research in the United States had been supported by private foundations, local industries and undergraduate tuition fees. After the war, scientists experienced a continuity - even an expansion - of the wartime funding model. Almost all support for basic, unclassified research (as well as for mission-oriented defence projects) came from the federal government.

In 1949, 96\% of all funding for basic research in the physical sciences in the United States came from defence-oriented federal agencies, including the Department of Defense and the then-new Atomic Energy Commission, successor to the Manhattan Project. In 1954 - four years after the establishment of the civilian US National Science Foundation - 98\% of funding for basic research in the physical sciences came from federal defence agencies. And the scale of funding was unlike anything before the war. By 1953, funding for basic research in the United States had leapt to 25 times what it had been in 1938 (in constant dollars, adjusting for inflation $)^{4}$. The fire hose of federal spending paid for all kinds of interesting research.

Much of the work was conducted in institutions modelled on wartime examples. Defence projects during the war had thrown together experts from many different fields of science and engineering to work towards common objectives, rather than grouping specialists by disciplines. The enormous time pressures and shared goals of war work forced scientists and engineers to craft

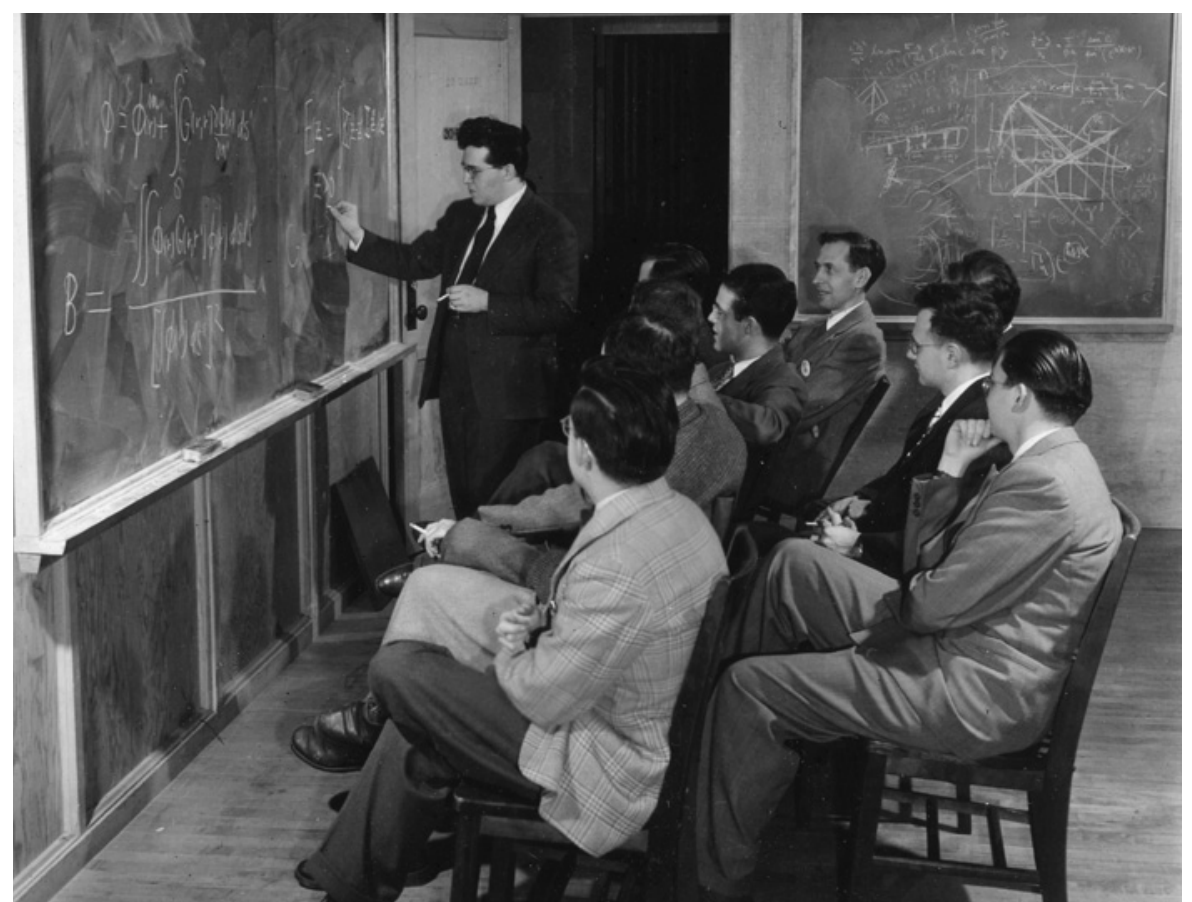

Julian Schwinger (standing) with colleagues at MIT's Radiation Laboratory during the Second World War.

effective means of communicating with each other. Mathematical rigour and abstruse theoretical derivations were worth little if colleagues from other specialities could not build on the results.

Veterans of the intense, multidisciplinary wartime projects came to speak of a new type of scientist. They touted the war-forged 'radar philosophy' and the quintessential 'Los Alamos man': a pragmatist who could collaborate with everyone from ballistics experts to metallurgists, and who had a gut feeling for the relevant phenomena without getting lost in philosophical niceties ${ }^{5}$.

Leading scientists and policy-makers actively sought to continue the wartime spirit of collaboration across disciplines.

\section{"Thiswar- The Atomic Energy}

\section{forged saw a new network} pragmatism of national laboratoproduced ries to pursue both enormously civilian and defence impressive research. The labs research." featured interdisciplinary teams that mixed physicists, mathematicians and chemists with engineers of many stripes ${ }^{6}$. A similar set-up appeared across dozens of US universities: facilities straddling several academic departments, such as the Research Laboratory for Electronics and the Laboratory for Nuclear Science and Engineering, both founded at MIT by the end of 1945 (ref. 7).

The facilities hummed with surplus equipment and know-how culled from the wartime projects. Physicist Bruno Rossi, for one, studied cosmic rays after the war by adapting the sensitive timing circuits he had built at Los
Alamos to measure nuclear-fission rates ${ }^{5}$.

Similarly, just months after the end of hostilities, self-described 'boffins' who had spent the war working on radar turned their attention to the impossibly small and the cosmically large. Some began to build radio telescopes and aimed them at the heavens. An international community coalesced, linking the Jodrell Bank telescopes near Manchester, UK, and the Parkes telescope in New South Wales, Australia, to similar instruments dotted across North America - from the California Institute of Technology in Pasadena to the National Radio Astronomy Observatory in Green Bank, West Virginia ${ }^{8}$. And in 1947, using repurposed microwave-frequency electronics left over from his wartime radar work, physicist Willis Lamb of Columbia University in New York measured a tiny shift — of about one part in a million - in the energy levels of an electron in the $2 \mathrm{~s}$ and $2 \mathrm{p}$ orbitals of a hydrogen atom. Lamb's remarkable achievement challenged physicists' prevailing understanding of the vacuum - the mysterious state of lowest-possible energy".

One of the first to hear about the Lamb shift was physicist Julian Schwinger, who before the war had been a rising star in quantum theory. Like so many physicists at the Rad Lab, Schwinger had been forced to rethink his approach to calculation. Elegant derivations from first principles - which often proved tractable only when applied to idealized situations - were of little value to the many colleagues who needed to finetune electronics components for maximum efficiency. Instead, as Schwinger himself later recalled, he internalized from the engineers a 
